\title{
Making The Right Match: Finding The Consulting Style That Fits Your Firm
}

Jack Militello (E-mail: jfmilitello@stthomas.edu), University of St. Thomas

Mick Sheppeck (E-mail: masheppeck@stthomas.edu), University of St. Thomas

\begin{abstract}
Consulting plays a valuable role in business worldwide. Yet there is an on-going tension between managers and consultants that is vigorously document by critics. This tension has various causes not the least of which is that particular consultants are not appropriate for particular situations. We offer a simple assessment tool to assist managers in finding the right match between their business needs and the services offered by consultants. We suggest that clients determine the desired relationship between the consultant offerings and their specificity to the client's strategic mission. We present a taxonomy of consultancy offerings and recommended how they may fit with the strategic mission of a client firm. We also warn clients to be aware of certain consultant behaviors that may inhibit client learning and increase the tension between the client and the consultant.
\end{abstract}

\subsection{Introduction}

A $\mathrm{s}$ the story goes, a shepherd died and left his flock of 17 sheep to his three sons. The oldest son received $1 / 2$ of the flock, the second son $1 / 3$, and the youngest son $1 / 9$. The flock did not easily accommodate the father's distribution plan and the sons were unable to decide how to divide the assets. So they went to the local Dervish who easily resolved the issue. He gave the sons one of his own sheep, making their flock total 18 . The oldest son took 9 sheep, the second son 6, and the youngest son 2, fulfilling their father's wish. Now there was one sheep left over which the Dervish took back, making him whole again.

This may be the first account of the business consulting industry, which today has reached enormous proportions. The industry is so segmented that its size is difficult to determine. Our guess of over 500,000 consultants, generating over $\$ 70$ billion in revenue worldwide would probably be in range if these categories could ever be accurately counted. Bookstores are bulging with items ranging from instructing dummies on how to consult to warnings of the demonic behavior of larger, multinational consulting firms. The most desired jobs for graduates of the most prestigious business school are still in the consulting industry. No matter what nuance is suggested for the industry, managers acknowledge that consultants have become important and valued allies in today's business environment. The prominence of consultancy has persisted through the recent rash of business scandals and economic downturn.

The simple reason most consultants are hired is that they possess a skill or skills that the client firms needs for a bounded period of time whether or not the firm possesses that skill internally. Yet, while consultants are hired and paid handsomely by firms, a real tension often exists between managers and consultants that leaves each cynical and detached from the other. We believe that tension is rooted in a fundamental mismatch between the capabilities that are offered by consultants and the type of intervention needed by the client.

A number of authors point to conditions that provide the basis for the tension. Chris Argyris says the consultants act as pawns for senior management and, in doing so provide advice that is not actionable. (164) Lewis Pinault claims that consultants plot to establish themselves as gurus while demeaning the intelligence of the client.

Readers with comments or questions are encouraged to contact the authors via email.

(216 to 218) Donald Schon believes that at the broadest level in business and society there is a lack of confidence in 
professional knowledge. (3) John Mickelthwait and Adrian Woolbridge describe consultancies as nurseries of the powerful where consultants use their practices as a springboard to running a company. (45) A colleague of the authors and former partner in a major consultancy described his former firm's product as consulting and the partner's job was to find a place to apply it. In his experience, the product was never defined in terms of fulfilling the client's needs.

\subsection{The Client/Consultant Tension}

Traditionally the consultant has assisted the manager in a variety of ways but has had no power to make changes or implement programs. This is changing, as outsourcing of services becomes an integral part of management and as responsibilities of consulting firms within organizations increase. Closer relationships between consultants and boards of directors and executive officers is one reason consultants are being given control over the action of the business and, in many cases, are competing with managers in setting and implementing organizational policy. The tension also manifests itself over issues of consultant methodology. Usually there is little room for the manager to negotiate the type of product or methodology offered by the consultant. The client tends to accept either on faith or mandate what the consultant offers methodologically whether it makes sense to the manager or not. Clients are often left wondering if billable hours can be translated into operational benefits.

We were alerted to the client/consultant tension recently when one of us was engaged by an industry association to present a two-day seminar on hiring and managing consultants. The first day was spent with consultants to the industry. The second was with industry managers who expressed the need to hire consultants. We found the two groups to be incompatible, not because of a lack of competence or industry knowledge on the part of the consultants. Rather, there was a mismatch between what the consultants offered and what the client needed. The former possessed a variety of methodologies they believed to be what was appropriate for the industry. The latter had a much different view of how they wanted to build their businesses. We were hard pressed to see how the client group would ever hire anyone from the consulting group.

Clients need consultants for a wide variety of reasons, from performing an outsourced task to providing insight into a management matter. Problems arise when either the client is unsure of his/her own strategic agenda or the consultant is too strongly tied to an approach that may not focus firmly on the needs of the client. At other times, the talent of the consultant may be a true mismatch with the needs of the client and neither party is able to address that issue for a variety of reasons. Yet, as in the case of the association mentioned above, sets of consultants have strong connections to client groups either because of an historical relationship or a perceived uniqueness of the consultant's knowledge base. A productive match between the consultant's offering and the client's need is not always easy to accomplish.

\subsection{Finding the Right Match}

As academics and consultants we have been concerned with serving our clients well along we assuring that clients succeed. In a past publication we had suggested an assessment process for choosing management interventions, such as Total Quality Management programs, business process engineer, organizational development, etc. (Choukroun and Militello) In that article we provided a framework through which the firm could understand which intervention tools to used based on the relationship of the tool to the firm's strategic core and risk control. For example, we stated that Total Quality Management works best with firms that are experiencing a sustained advantage in their markets. Organizational Development programs work best with firms that have low risk exposure in their markets but an unfocused strategic core. Business Process Engineering works best when firms have a highly focused strategic core but have a high risk exposure in their markets. This framework assumes that not all interventions are right for all situations. We believe that the same is true for consultant interventions.

We assume that all consultants offer a good, ethical product. However not all consulting approached are appropriate for all firms. Therefore we propose a simple model can be beneficial to the firm in finding the right match with a consultant. Our model has two components:

- The relationship between the consulting activity and the strategic mission of the firm. 
- $\quad$ The consulting capabilities available.

\subsection{The relationship between the consulting activity and the strategic mission of the firm.}

Successful firms differentiate themselves strategically from their rivals. The point of differentiation becomes the focus of the firm's strategic mission. For the purposes of this article we will not address strategic theories. Rather we will simply state that the client firm should determine how specific the consultant services are aligned with strategic mission. Our model presents three categories of mission specificity.

- $\quad$ Market Generic Service: Services that are generic to the market place are looked upon as high quality and applicable across most segments of businesses. While nuance or market context is important, a number of services can transcend industry types. This type of service is important but not specifically essentially to the differentiating mission of the firm.

- Industry Specific Service: Services that are specific to an industry can provide a firm with expertise that addresses the competitive constraints of its industry. Industry knowledge is can be very important to a firm's mission.

- $\quad$ Organizational Unique Service: Firms find their competitive advantage in their ability to have a differentiated strategic mission. Organizational unique services have a very specific relationship to the firm's strategic mission. A firm finds its competitive advantage in its organizationally unique business elements.

\subsection{The consultant capabilities available}

According to Danielle Nees and Larry Greiner, the growth of the consulting industry has made it difficult for clients to choose from a myriad of seemingly competent "look-alike" consulting firms. (68) In their research, Nees and Greiner discovered the culture and values of consultancies affect how problems are diagnosed and the more thorough the client's understanding of the differences between, the better and more informed the client's choice will be. Following up on the latter point, Nees and Greiner presented a classification of scheme for identifying five types of consultancies.

We have worked from the Nees and Greiner classifications and redefined the consultancy categories. Their five categories included researcher, planner, diagnostician, designer, and advisor. We, too, have settled on five, keeping some variations of the Nees and Greiner categories. Our five are facilitator, mentor, researcher, modeler, and implementer. The advisor and researcher types are similar. We have included the diagnostician, planner, and designer into our modeler category and have added the facilitator category. We differ most in the final type. Nees and Greiner stated that consultant do not manage. We have seen over the years that more and more consultancies are accepting assignments that include full responsibility for implementation.

\section{Facilitator}

Managers often need a consultant to run an important meeting or set of meetings and call upon facilitators for help. The facilitator does not need any specific knowledge of the client's industry or the client firm itself, for that matter. Rather the knowledge base of the facilitator is one of group process. He/she is usually engaged by the client to build consensus, keep a process on track, and/or assure that all members of group have the opportunity to state their views. The facilitator is not usually responsible for follow-up work. A meeting report or listing of discussion outcomes is most often the requested deliverable. Facilitation skills are scarce in many consultations, especially those in which the consultants are dogmatic about their methodology or are too focused on a specific set of facilitation processes in themselves to adapt to client suggestions regarding process. Likewise, clients may expect too much from the facilitator in terms of quick, easy answers to problems or the painless calming of emotions that arise in meetings.

\section{Mentor}


Anyone can be a mentor. The truly effective business mentors possess general business knowledge, as well as insight into the psyche of the client. The mentor is a sounding board for the manager, responding to his/her comments and feelings. The mentor provides advice and lets the manager figure things out for him/herself. The need for command of latest business trends or knowledge of a specific industry is not necessary for the mentor to be effective. In fact, not focusing on that type of information prevents the mentor from being too prescriptive and opens him/her to responding to the unique needs of the client. In engaging a consultant as a mentor a manager is looking for someone to trust, as well as some honest feedback to help the manager to become wiser. Consultants hired for other services can do well as mentors. Yet the urge to provide other contracted deliverables might divide the consultant's focus. Like the facilitator, the mentor should not be relied upon for in-depth responses to business problems. Managers may be disappointed that they do not get the "answer" from the mentor. Good mentors assist the client in finding the answers for him/herself.

\section{Researcher}

In The Renewal Factor Robert Waterman openly wondered why firms would ever hire McKinsey \& Company, the strategic consulting firm that employed him at the time. (42) He felt they did so because of the high quality of the research offered by McKinsey \& Company and not necessarily for their strategic advice. The researcher can provide the manager with invaluable information that can drive truly effective decision-making. This type of consultancy is rooted in academic disciplines such as economics and statistics. It provides problem identification, analysis, and, more often than not, new insights into the firm or its industry. Researchers usually work aside from the client and are governed more by methodology than by client interaction. Tensions develop when the client may attempt to influence the methodology in order get a predetermined outcome. Disciplined researchers will vigorously resist that interference. On the other hand, managers may have to make decisions quickly and with imperfect knowledge and the researcher may have to adjust methodologies to those requirements.

\section{Modeler}

The modeler offers the most comprehensive set of services of the consultancy types. A firm's business model defines how it goes to market, manages financial matters, and motivates employees and shareholders. A model is systemic guide to the business and the consultant/modeler works throughout the system. He/she designs the project, works with the client from concept to implementation, and assists in the final decision-making. The methodology of the modeler provides assurances for the manager that the engagement has a workable direction with an end in sight. A well-defined methodology also keeps the consultant and management team on task, especially if the engagement is complex. The modeler can be an extremely strong ally but can also be difficult to work with when reluctant to adapt the model for particular client applications. Relinquishing control to the consultant's methodological process may be difficult for the manager. Likewise, relinquishing implementation control to the manager may be difficult for the modeler.

\section{Implementer}

The implementer owns a specific expertise and/or industry knowledge and is most likely well experienced in the assignment. This type of consultancy has a "been there, done that" demeanor. The implementer takes over the assignment and makes the decisions. Unlike the modeler, the implementer becomes a manager. The expectations of the implementer are a job well done and a complete, finished product. The implementer tends to do it his/her way and may be insensitive to the culture or traditions of the client organization. Or the implementer can be a factotum for the manager, following a prescribed plan. The manager outsources the work but may little control over it. Contracting the implementer is very important. The boundaries and expectations of the engagement must be well defined for all parties in order reduce the possibility of conflict.

\subsection{Choosing a Consultant}


The two elements of our assessment are brought together is a simple matrix. Here we have given our own perspective of how the consultant capabilities would align with the specific requirements of the strategic mission. We present the points of fit as our recommendations.

\begin{tabular}{|l|c|c|c|c|c|}
\hline & Facilitator & Mentor & Researcher & Modeler & Implementer \\
\hline $\begin{array}{l}\text { Organizationally } \\
\text { Unique }\end{array}$ & $\begin{array}{c}\text { Not } \\
\text { Recommended }\end{array}$ & $\begin{array}{c}\text { Not } \\
\text { Recommended }\end{array}$ & $\begin{array}{c}\text { Not } \\
\text { Recommended }\end{array}$ & Recommended & $\begin{array}{c}\text { Not } \\
\text { Recommended }\end{array}$ \\
\hline Industry Specific & $\begin{array}{c}\text { Not Recommend- } \\
\text { ed }\end{array}$ & $\begin{array}{c}\text { Not Recommend- } \\
\text { ed }\end{array}$ & Recommended & Recommended & $\begin{array}{c}\text { Not } \\
\text { Recommended }\end{array}$ \\
\hline Market Generic & Recommended & Recommended & Recommended & $\begin{array}{c}\text { Not } \\
\text { Recommended }\end{array}$ & Recommended \\
\hline
\end{tabular}

The facilitator is a market generic functionary. Asking for industry specific or organizationally unique input from the facilitator alters the function. The facilitator is taken out of role to become an opinioned participant in the discussion and not a guide. The same is true for the mentor. This role ought to be industry and company neutral. He/she is concerned with the well being of the person mentored and not with organizational problem solving. It may be difficult for the facilitator and mentor to maintain these boundaries. Their offerings would have more integrity if they do.

The researcher is most powerful in providing information external to the organization. In our experience firms tend to focus most knowledgeably on their internal competencies while preferring assumptions over data in regard to competitors and customers. The researcher opens the firm up to understanding its opportunities and threats. With those cards on the table, the firm can better define its strategic advantage. The researcher is not asked to solve internal organizational problems, though they often try. What results is generally vague and ineffectual recommendations that may serve to discredit valuable research data.

The modeler becomes very involved in the processes of the client firm and its industry. This type of consultancy loses its impact when it brings generic tools to a specific culture. The modeler that works on industry specific issues can assist the firm on strengthening its competitive behaviors. When working on organizationally unique issues, he/she can truly help the firm shape its strategic direction. While the modeler seems to have all the fun, he/she also takes a great deal of risks. The modelers that seem to fail or create tensions with the client are the ones that are too wedded to their own methodologies.

The implementer does a job. It is our belief that a firm should not outsource the implementation of key strategic initiatives. Those activities that are most specific to the firm's strategic mission might better off controlled by internal staff. Otherwise, the firm's advantage would be exposed to the market place or to industry competitors. Unless governed by strong contracts, the implementer would be free to sell what he/she learned from the client to anyone.

These recommendations are given as an illustration of our assessment matrix. The application of the assessment matrix by a client firm should elicit probes into the firm's strategic mission. From their the firm can better decide what it wants to hold internally and what it wants to buy from the consultancy market place. We believe that more the consultancy engagement is specific to the strategic mission of the firm; the more care has to be taken in the selection and management of the consultant. This is most true for the modelers and implementers. In our opinion the facilitators, mentors, and researchers should be kept from direct involvement in issues related to the client firm's strategic mission.

\subsection{Hiring the Consultant/Watching Out for the Evils}


A number of the references in our bibliography offer helpful tips to the client firms regarding hiring and contracting consultants. These tips are comprehensive and quite good. Our contribution at this time is to focus on the strategic selection process and there is little we can add to those tips. However we do want to stray a bit from our assessment matrix and add some opinions of what clients should be aware of in selecting a consultancy. Following are what we perceive to be three evils of consultants to which clients should be alerted.

\subsection{Consultants who cannot differentiate services}

Consulting firms that once specialized in certain areas are expanding their offerings to new, seemingly related areas. For example, some accounting firms have moved from compensation consulting to organizational development, becoming modelers in addition to implementers. Facilitators are offering their services as strategists, assuming the modeler role. Modelers sell research. Mentors want to facilitate, etc. While these product extensions can be done successfully in many instances, the consultancy evil occurs when the consultant does not understand the nuances of their new offering. A facilitator recently told us that she is now doing strategic planning. When asked how she was doing it, she stated that when she is a facilitator she only answers questions about the process and when she is a strategic planner she will answer questions about the business. Recently a tax attorney asked his a client if he could help them with their human resource planning. In these two instances the consultant is unable to differentiate their services in terms of their expertise. The desire to cross-sell service seems to overshadow competence.

Facilitators, mentors, researchers, modelers, and implementers each may have methodologies that are systemic and can be applied to a variety of settings. However, not all facilitators can be modelers, just as not all mentors can do credible research. Consulting engagement tend to sour when someone fails to successfully translate skills from one type to another. Clients should be very cautious of consultants who cannot make a service differentiation.

\subsection{Consultants who never fail}

A number of noted consultants, a few with whom we have worked, present their work as failure-proof. They tell tales of the courageous managers who follow their advice and succeed and the foolish managers who do not follow their advice and fail. They never talk of those who did not follow their advice and succeeded or those who followed their advice and failed. Less accomplished consultants are assuming the arrogance of their more famous colleagues by refusing to think critically about the outcomes of their consulting engagements. Each of our five types is susceptible to this syndrome.

Unfortunately clients often want to buy a sure-fire path to success. They would rather have the failures of the consultant's past clients educate the consultant so when they hire a consultant, failure in not an option. Consultants buy into this marketing model but will seldom divulged how they became so infallible. Richard Farson reminds us that it is important to fail. If we do not, it means we are not testing our limits. It means we are not taking the necessary risks to improve our behavior. (114) In a number of instances, especially with the mentor, modeler, and implementer, the consulting engagement is a joint learning experience. Both the client and the consultant should work together, each one learning from the engagement. If learning is only one-sided, client can lose confidence in his/her abilities. Over dependence on the consultant can result, followed by a souring of the engagement.

\subsection{Consultants who want you to be like them}

The ranks of charismatic consultants are growing. Their inspirational message demands a committed following. Many of these consultants are aggressive facilitators who work with groups in retreat settings. Their work is done in the here-and-now moment of the retreat. The group members work on themselves and carry the message on to their personal and/or business lives.

The pitch usually involves the discovery of the new paradigm. The group is taught the almost everything that was done or thought about in the past is old hat and ineffective to boot. The new vision demands that the group adopt the viewpoint of the creative, charismatic facilitator. If the client can imitate the consultant, he/she too can become a new paradigm leader. 
The consultant is demanding that the client act in a certain way without understanding the personal and organizational nuances the client faces. These consultants provide a set way of doing things and do not allow the client options. Modelers and mentors are susceptible to this syndrome. Also, former CEOs turned consultant may practice this evil. They are skilled in telling people what to do and getting reasonable compliance from their directives. When they become consultants, they push a narrow point of view and demand that the client comply as it the manager where the consultant's employee.

Learning from a charismatic personality can be very exciting. However the client group eventually has to find its own route to problem solving, either individually or in an organizational setting. The one-best-way model has always been attractive but never seems to deliver on it promises.

\subsection{Conclusion}

The consultant industry has come a long way is solving the problem of the inherited sheep. The right consultant can make a value contribution to a firm. The wrong consultant can have an extremely detrimental effect on the organization. Our assumption is that most consultants are competent in the proper situation. Clients can best determine that situation by simply assessing the consultant offerings in relation to firm's strategic mission. Without extreme effort, the client firm can determine how it wishes to buy outsourced services. Different services fit better with different levels of mission specific consulting tasks. Managing the boundaries of consultancy offerings can most likely result in a productive relationship between the consultant and the client. The client should also look to avoid those consultants that are rigidly attached to their own methodologies and learn along with the consultant.

\section{References}

1. Chris Argyris Flawed Advice and the Management Trap_Oxford 2000.

2. Jean-Marc Choukroun and Jack Militello "Using Core/Risk Analysis for Competitive Advantage" 1998 Handbook of Business Strategy_Faulkner and Gray 1998.

3. Richard Farson Management of the Absurd_Touchstone 1997.

4. John Micklethwait and Adrian Woolbridge "The Witch Doctors" Times Business 1996.

5. Dannielle B. Nees and Larry E. Greiner "Seeing Behind the Look-Alike Management Consultants" Organizational Dynamics Winter 1985 V. 13 \#3.

6. James O'Shea and Charles Madigan Dangerous Company_Times Business 1997.

7. Lewis Pinault Consulting Demons Harper Business 2000

8. Donald A. Schon The Reflective Practitioner Basic Books 1983.

9. Robert H. Waterman, Jr. The Renewal Factor Bantam 1987 